\title{
VIDA EN EXCÉS I AMOR SENSE CASA: UN DIÀLEG POÈTIC ENTRE MARINA TSVETÀIEVA I MARIA-MERCÈ MARÇAL ${ }^{1}$
}

\author{
LLÜÍSA JULIÀ \\ Universitat Obert de Catalinya \\ ljuliac@uoc.edu \\ ORCID: 0000-0002-0423-2832 \\ Olga STAROVOITOVA \\ Universitat Estatal de San Petersburg \\ o.starovoytova@spbu.ru \\ ORCID: 0000-0002-3645-8203
}

RESUM

L'article presenta una aproximació a l'estudi comparatiu de l'obra de Marina Tsvetàieva, una poeta russa, i de Maria-Mercè Marçal, una poeta catalana. En relació a les seves obres literàries, especialment poètiques, es pot emprar el concepte de convergència tipològica, que marca fenòmens similars en diferents literatures que són el resultat de diferents etapes del desenvolupament sociohistòric i cultural dels pobles o -més aviat, en el cas estudiat- de lleis universals de consciència humana. Les obres de ambdues tracen un diàleg constant sobre el "camp" dels textos pertanyents a diferents literatures nacionals però units per les nocions bàsiques i comuns a una dona que se submergeix en la poesia. Una i altra poeta viuen al límit, amb intensitat, temeroses de deixar camins per fresar; poetes de l'amor i la desmesura, del risc més enllà dels límits imposats, exigint-se al màxim.

PARAULES CLAU: poesía del segle XX, Marçal, Tsvetàieva, mentalitat comú, estudis comparatius, llenguatge poètic.

\section{LIFE IN EXCESS AND LOVE WITHOUT HOME: A POETIC DIALOGUE BETWEEN MARINA TSVETAYEVA AND MARIA-MERCÈ MARÇAL}

\section{ABSTRACT}

The article presents an approach to the comparative study of works by Russian poet Marina Tsvetayeva and Catalan poet Maria-Mercè Marçal. Their literary works, especially poetic, can be studied in terms of the typological convergence; it denominates similar phenomena in different literatures, which are the result of different stages of the socio-historical and cultural development of the peoples or -as in the case studied- of universal human conscience laws. The works of both poets exercise a constant dialogue on the field of texts, which belong to different national literatures but are united by the basic and common notions of a woman who immerses herself in poetry. Both poets live on the edge, with intensity, in excess, fearful of leaving paths to mill; they are poets of love and excess, of risk beyond the imposed limits.

\footnotetext{
${ }^{1}$ Aquest text parteix de la conferència dramatitzada que Lluïsa Julià i Olga Starovòitova van pronunciar en el cicle Cartografies del desig 3, en el teatre Espai de Barcelona la tardor del 2001.
} 
KEYWORDS: 20th Century Poetry, Marçal, Tsvetayeva, Common Mentality, Comparative Studies, Poetic Language.

\section{INTRODUCCIÓ}

L'estudi de la literatura, que havia adquirit un caire científic, inevitablement va conduir a l'estudi de la interacció i la influència de les literatures de les diferents nacions, amb formes similars en el seu desenvolupament, amb analogies històriques i tipològiques del procés literari: “La història de la societat humana no coneix realment exemples de desenvolupament aillat social i cultural i, en conseqüència, literari, si tampoc hi ha absència d'interacció entre uns elements en aquest procés. Les nacions cultes estableixen una comunicació i cooperació més intensa amb les altres nacions"' (Zhirmunsky 1960: 182). ${ }^{2}$

Com a branca científica, la literatura comparada va introduir en el corpus científic un material molt interessant mitjançant un gran nombre de textos $\mathrm{i}$ d'escriptors en juxtaposició (vid. p. ex. Julià 2010, Làskina, Riba, Starovoitova, Zhirmunsky 1978, Zolot'ko), al mateix temps que va desenvolupar el seu propi sistema metodològic i metalingüístic (la terminologia) (vid. p.ex. Dima, Durišin, Zhirmunsky 1960).

El camí de la investigació científica a partir de la simple juxtaposició, tot constatant similituds, hauria de conduir a la seva explicació històrica (vid. Zhirmunsky 1960 i 1978). De vegades, però, l'investigador està de sort quan el mateix escriptor, d'una manera o altra, explica el seu interès per un altre escriptor. Aquest interès "personal" uneix dues poetes: la russa Marina Tsvetàieva i la catalana Maria-Mercè Marçal, des del moment que l'escriptora catalana qualifica els poemes de la poeta russa de "dietari commovedor i de qualitat extraordinària" (Marçal 1998: 157).

La mort prematura uneix Marina Tsvetàieva (el 1941, a l'edat de 48 anys, sola i abandonada en el seu retorn a l'URSS, decideix suïcidar-se), i Maria-Mercè Marçal (el 1998, a l'edat de 45 anys, mor de càncer). Més encara, les seves vides i les seves obres fan una trena indestriable, perquè totes dues obeeixen a una mena de predestinació, de destí fatal que les envolta.

El 1992 Maria-Mercè Marçal publicava la seva versió del Poema de la fi de Tsvetàieva i així celebrava el seu particular homenatge -compartit estretament amb Monika Zgustova- en el centenari del naixement de la poeta russa, quan aquí era escassament coneguda (vid. Tsvetàieva 2009²).

Una estrofa d'aquest llibre, que caracteritza la percepció de la vida per part de l'escriptora russa, és compartida per la traductora: "Com un gos rabiós ulula / -Ganyol boig.../ (Vida en excés s'acaramulla / Quan et mors)“ (Tsvetàieva 20092: 54). El to emocional del poema ve determinat per "sentiments exagerats" (vid. Skripova 2005) que en relació amb les dues poetes es pot entendre com la tensió

\footnotetext{
2 En aquest cas i tots els posteriors els textos de la llengua russa estan traduïts per Olga

Starovòitova i Lluïsa Julià si no s'indica el contrari (vid. Bibliografia).
} 
límit de les forces, la intensitat més alta dels sentiments, la nitidesa hipertròfica de la percepció associada a la sensació de la "fi" que també es troba descrita per Marçal en la novel·la La passió segons Renée Vivien:

Tota vida és sempre radicalment incompleta, en certa manera. O sempre completa: en la mesura en què la mort hi escriu sense retop el punt i final. I és, al capdavall, des d'aquesta fi, que el relat pren el seu sentit definitiu. Algú que ha mort als trenta-dos anys, serà, des del dia del seu naixement, algú que ha de morir als trenta-dos anys. A més a més, en el cas de Renée, la intensitat i el ritme vertiginós amb què va exhaurir la seva existència semblen desafiar la mateixa limitació d'un temps tan breu. (1994: 334)

Una i altra poeta viuen al límit, amb intensitat, amb excés: temoroses de deixar camins per fresar. Són poetes de l'amor i la desmesura, del risc més enllà dels límits imposats, exigint-se al màxim.

\section{ENFILALLS BIOGRÀFICS BASICS}

Les vides de Marina Tsvetàieva i Maria-Mercè Marçal destaquen en el rerefons dels grans esdeveniments europeus de tot el segle XX en els quals es veieren directament implicades o compromeses; però més enllà de les dues guerres mundials i la divisió europea, simbolitzada per la construcció del mur de Berlín, les dues poetes viuen situacions prou oposades.

La vida de Marina Tsvetàieva, nascuda el 1892, està marcada pels esdeveniments històrics i polítics de la primera meitat del segle XX. Viu les revolucions russes $(1905,1917)$ i la guerra civil russa (1917-1922), l'emigració i el començament de la II Guerra Mundial.

Després de la revolució del 1917 que Tsvetàieva no accepta, el seu marit abandona Rússia seguint l'Exèrcit Blanc (l'exèrcit del tsar i dels diversos governs anti-soviètics en el temps de la guerra civil) i durant 4 anys ella, que ja tenia dues filles petites, no va saber res d'ell. Tota la desgràcia de la guerra civil recau sobre les seves espatlles. Així descriu un dia de l'any 1919 des de la seva habitació moscovita:

Escric malament, amb pressa. No he apuntat ni les meves ascensions a les golfes (no hi ha graons perquè els hem cremat per escalfar-nos), per això pujo per la corda, per aconseguir llenya; ni les cremades constants de les brases que agafo (¿per no tenir paciència? ¿per agressivitat?) amb els dits, ni el trafiqueix amb les botigues de segona mà (¿si he tingut sort, si han venut els meus objectes?), amb les cooperatives (a veure si distribueixen el menjar!). No sé si ara a Rússia existeix un autèntic observador que pugui escriure un llibre sobre la fam i de mi: poeta i dona, sola, sola, sola, com un roure, com un llop, com déu, enmig de totes les pestes de Moscou de l'any 19. (1994d: 136)

Poc després va començar un enfilall d'exilis. El maig de 1922 Tsvetàieva va deixar el país per reunir-se amb el seu marit i viu 17 anys a l'estranger: primer a Berlín, on fa una estada curta, després viu tres anys a la República Txeca i, finalment, a França. És un exili sense retop, aillada també dels cercles literaris, 
tant de Rússia com de l'emigració russa fora del país. La seva és una vida sota el signe de la desesperança.

Tot i que les seves obres es publiquen, la poeta se sent estranya i buida. "Els bolxevics em consideraven blanca, i aquí, a l'estranger, m'anomenen una bolxevica", diu Tsvetàieva (Saakyants 2002: 722). És simptomàtic que al passar la frontera russa els seus versos es tornin clandestins. Marina es replega dins d'ella mateixa: "No hi ha cap lector en l'emigració, el meu fracàs coincideix amb l'absència absoluta de les persones que estimen els meus versos" (1994d: 93). Durant els 14 anys que va viure a París, ni la situació, ni el seu estat psicològic no milloren; ben al contrari esdevé una exiliada en l'exili (Kudrova 1991: 197 i 224).

La imatge d'un "ocell exòtic" permet entendre la seva posició d'exclusió a París. Així la descriu Tatiana Astàpova, una companya seva de l'escola privada de Moscou, quan tenien 16 anys:

Tsvetàieva va estudiar a la nostra escola durant dos anys, però seria millor dir que hi va estar. Va ser una alumna especial: [...] no sé de quina manera, però romania fora de l'esfera escolar, fora de l'horari establert. Enmig de nosaltres era com un ocell exòtic que per casualitat havia aparegut enmig d'un esbart d'ocells del bosc nòrdic. Al seu voltant hi havia moviment, soroll, parrupeig, però ella tenia un altre vol, una altra llengua. (Saakyants 2002: 16)

Aquesta impressió d'ocell exòtic es manté al llarg dels anys. Ella mateixa es considerava "un ocellet arrencat que pateix fred" (Kudrova 1991: 84).

El 1939 Marina Tsvetàieva decideix emprendre el viatge de retorn a les flames de la Rússia estalinista amb el seu fill Gueorgui. No va suportar les pressions constants de Serguei Efrón, el seu marit, i la seva filla Ariadna, que ja havien tornat abans, però la decisió els condueix a una fi tràgica. La tomba de Tsvetàieva no ha estat localitzada en el cementiri de Ielàbuga, l'antiga ciutat prop del riu Kama, ara territori de la República de Tatarstan. Segons testimonis de l'últim any de la seva estada a París, "Marina podia sobreviure sense Serguei i sense Ariadna, però no podia estar lluny del seu fill". Encara més, Borís Pasternak sentenciava que Tsvetàieva va sacrificar la seva poesia i a ella mateixa per l'amor del seu fill (Karlinsky 1986: 269-270).

Maria-Mercè Marçal va néixer circumstancialment a Barcelona el 13 de novembre de 1952 encara sota l'embat de la dictadura franquista, especialment repressora amb les terres catalanes, que va actuar per liquidar les seves institucions, la seva cultura i la seva llengua. Però al llarg de la seva adolescència i joventut Maria-Mercè viu la naixent consciència nacional catalana, sobretot en la dècada dels setanta, coincidint amb els seus anys universitaris; la seva vida, doncs, coincideix amb un període esperançador, en la qual ella s'implica molt activament. Va passar la seva infantesa al poble d'Ivars, a la comarca de l'Urgell. Des de l'any 1969, quan inicia els estudis a la Universitat de Barcelona, MariaMercè s'independitza i viu quasi sempre a la capital catalana. 
Marçal va destacar sempre en els estudis, fet que li va permetre obtenir beques per cursar primer el batxillerat a Lleida i després estudiar Filologia Clàssica a la Universitat de Barcelona. Pertany a les primeres generacions de noies que arriben amb certa normalitat a la Universitat i que prenen part activa en el moviment polític d'estudiants.

L'any 1976 es produeixen tres fets significatius en la seva vida- obté el premi de poesia Carles Riba pel seu primer recull Cau de llunes, participa en les Jornades de la Dona que donen impuls a un nou i estructurat moviment feminista i, en el vessant polític, ingressa al PSAN, Partit Socialista d'Alliberament Nacional dels Països Catalans. (vid. Julià 2017).

Marçal enceta el seu llibre Cau de llunes amb una divisa que ha esdevingut síntesi del seu posicionament radical: "A l'atzar agraeixo tres dons: haver nascut dona, / de classe baixa i nació oprimida. I el tèrbol atzur de ser tres voltes rebel" (1989: 23). Una rebel-lió que Marçal va dur al terreny personal i que va mantenir al llarg de la seva vida, tot i que amb els anys la seva poètica evolucionés. D'aquí que sigui pertinent la manifestació que apunta que: "després de la seva mort [la divisa] ha restat enganxada al seu tarannà personal i poètic com un estendard" (Sistac 2001: 106).

En el mateix recull hi trobem algunes composicions, d'arrel política, sobre el final de la dictadura franquista, com la següent que celebra la mort del general Franco el novembre de 1975: "És ara quan ens cal escampar el vi / i empillocarnos fins que fugi el seny, / que el tirà és mort!" (Marçal 1989: 41).

Tsvetàieva deia amb freqüència que no pertanyia a la seva època; el 1934 escriu que qualsevol ciutadà és del segle $X X$, mentre ella se sent fora de tots els segles i de llocs (1994b: 315). Però contra del que pugui semblar també viu immersa en el món, i, precisament el juny de 1939, mentre tota Europa ja estava en flames, es posiciona contra el feixisme: "Oh, llàgrimes als ulls! / Plor de ràbia i amor! [...] Al teu món boig / responc -renuncio“. (1994b: 360)

Evidentment la vida de Maria-Mercè Marçal és molt menys moguda que la de Marina Tsvetàieva, però tampoc podem definir-la com sedentària. De fet, Maria-Mercè esdevé, com apunta a Viratges, reminiscències, recorre constantment cases i barris de la ciutat de Barcelona. Primer comparteix pis amb la seva germana Magda, després amb altres estudiants o amb amigues i amics; $i$, a partir de 1980, amb la seva filla Heura. Són anys de provisionalitat, d'inestabilitat, de precarietat emocional:

¿Pot esdevenir un port, si no definitiu, almenys durador per al meu tarannà nòmada que $\mathrm{m}^{\prime}$ ha dut a sembrar d'enclavatges emotius, de senyals incisivament subtils, tants punts diferents d'aquesta aglomeració de blocs d'obra i de vides que, des d'aquest terrat obert a tots els vents, s'estén ara als meus peus? Xarxa dins de la qual em debato, presa entre la convulsivitat frenètica $\mathrm{i}$ el bloqueig, que ressegueixo amunt $\mathrm{i}$ avall, per dins, corrents darrere d'amors i d'altres coses... (Marçal 2004: 28) 
Viratges, reminiscències també apunta al conflicte de l'exclusió dels amors femenins, com a Desglaç, publicat el mateix any 1989, on "la casa" esdevé un lloc inabastable tal com exposa en el poema "El meu amor sense casa". En altres poemes, l'escriptora s'endinsa a l'arrel del mateix pensament androcèntric per analitzar-lo i contravenir-lo.

Tot i les distàncies d'espai i temps, hi ha una atracció cultural nord - sud destacable que podem veure en gestos concrets coincidents en les dues poetes: Marçal atrapada en la lectura de La filla del capità de Puixkin; Puixkin tan decisori, en l'obra literària de Marina Tsvetàieva; $\mathrm{o}$, al seu torn, Tsvetàieva, traduint García-Lorca al final de la seva vida. Lorca, el poeta andalús, estimat i molt present des del principi en la poesia de Maria-Mercè.

Si no es pot justificar les similituds entre les poetes per només la regularitat del procés històric, l'essència del qual consisteix en la interacció constant de pobles i cultures podem utilitzar d'altres criteris - $\mathrm{l}^{\prime}$ afinitat psicològica, una semblança dels destins extraordinaris provocats pel seu do poètic de caràcter multicairat.

\section{EL DO POÈTIC I L'OBRA}

La predestinació cap a la poesia es pot constatar en el destí de totes dues poetes. La infantesa i joventut de Marina Tsvetàieva transcorren en un ambient intel-lectual i artístic. En la seva autobiografia escrita l'any 1940 per a l'enciclopèdia literària russa diu: “La meva passió per la poesia prové de la mare, la passió pel treball i per la naturalesa tant del meu pare com de la meva mare. [...] La meva tasca preferida des que tenia 4 anys -la lectura, i des que en tenia 5 -l'escriptura." (Tsvetàieva 1994e: 6)

Maria-Mercè Marçal va passar la seva infantesa al poble d'Ivars, a la comarca de l’Urgell. És en l'ambient familiar que s'inicia en la literatura, escriu poesia des dels sis anys, primer en castellà, mentre aprenia de viva veu les nombroses cançons, rondalles $\mathrm{i}$ altres composicions populars catalanes que li pervenen principalment per la seva mare, excel-lent recitadora $\mathrm{i}$ animadora de vetllades musicals i teatrals per a la xicalla del poble.

En les dues poetes inicis literaris i relacions amoroses es produeixen aviat i al mateix temps: Marina Tsvetàieva té 18 anys quan publica Àlbum vespertí (1910) i el 1912, dos anys més tard, es casa amb Serguei Efrón i publica Llanterna màgica que obté un reconeixement per part de la crítica.

L'any 1976 Maria-Mercè Marçal té 24 anys i obté el premi de poesia Carles Riba pel seu primer recull Cau de llunes. Quan Maria-Mercè es dóna a conèixer com a poeta, ja en feia tres que s'havia casat amb el també poeta Ramon Pinyol i col·laborava estretament amb ell en l'editorial Llibres del Mall (1973-1989), impulsada pel mateix Pinyol i amb participació d'altres joves poetes que seran coneguts com la generació del 70. 
Fins a la meitat dels anys vint Tsvetàieva té una productivitat impressionant; sembla que la musa la visita constantment. Té períodes tan fecunds que fa un llibre sencer en pocs mesos; així l'antologia Verstes (que significativament vol dir Kilòmetres) l'escriu entre els mesos de febrer a abril de l'any 1916. Es considera com un dels millors llibres de la poeta que no en té d'anàlegs entre les seves obres posteriors. A partir dels anys vint, el corrent poètic canvia bruscament. El món es torna ferotge i àrid. La nota tràgica inunda els seus versos. El 1923, a Berlín, Tsvetàieva va publicar l'antologia Remesló (Mà d'obra) que palesa un canvi del seu estil poètic causat pels grans esdeveniments amargs i també per l'evolució de la seva actitud envers els valors de la vida (Kudrova 1991: 34-35). Els nous versos no són tan lleugers, però tenen densitat i profunditat.

Com a poeta, Marina Tsvetàieva creix i es transforma amb celeritat fins a l'extrem de no poder ser reconeguda pels seus lectors. El seu do poètic és d'una “originalitat esclatant” (Marçal 1998: 165). El poeta MaximiliànVoloshin la va descobrir quan ella només tenia 18 anys. Voloshin considerava que amb la seva força podria alimentar molts poetes; però a més a més, era una veu molt versàtil. Marina podia fer-ho tot: podia escriure des de contes populars fins a versos intimistes. L'escriptura esdevé una necessitat imperiosa. Forma part de la seva vida. Si no escrivia se sentia infeliç, infortunada.

Marçal manté la mateixa relació amb l'escriptura: “escriptura ha estat, és per a mi una activitat vertebradora. Tot i que molt sovint se $\mathrm{m}^{\prime}$ ha fet, des de fora, la pregunta "per què escric", espontàniament a mi se m'ocorre més aviat de preguntar-me per què no escric quan passo gaire temps sense fer-ho". (Marçal 2004: 21)

A través de l'escriptura, Marçal busca la seva identitat i la seva experiència vital, i això implica enfrontar-se i explorar grans temes i tabús marcats socialment per anys i segles: què vol dir ser filla, i ser mare i tota la xarxa de relacions que la societat ha ordit per a la dona, la passió amorosa, l'amistat i els seus límits, el poder establert, la mort... Escriure poesia, deia Maria-Mercè, “et porta a l'ull de l'huracà", a la indagació i al compromís més íntim amb tu mateix. Els seus textos agrupats en els poemaris Cau de llunes (1977), Bruixa de dol (1979), Sal oberta (1982), Terra de Mai (1982), La germana, l'estrangera (1985) i Desglaç (1989), compresos a Llengua abolida (1973-1988) (1989) mostren "la força innovadora de la paraula poètica que converteix Maria-Mercè Marçal en un clàssic indiscutible de tota la lírica catalana“ (Julià $2001 \mathrm{~s} / \mathrm{p}$ ). La publicació de la seva única novel·la La passió segons Renée Vivien (Premi Carlemany 1994) va rebre múltiples distincions que la van situar com a figura literària indiscutible.

Marina Tsvetàieva i Maria-Mercè Marçal són poetes que transmuten vida en poesia; per això la vida sense escriptura és supèrflua per a elles, és la no-vida.

Tsvetàieva parla sobre aquests temes a través de la correspondència amb el poeta Rilke subratllant l'essència de la poesia: 
9 de maig de 1926 [...] Vostè no és el poeta que més estimo ("més" implica ja una comparació). Vostè és un fenomen de la naturalesa que no pot ser meu, que no pot estimarse, sinó comprendre's; o (no ho és tot encara): vostè és la personificació del cinquè element: la poesia mateixa; o (no ho és tot encara): vostè és allò d'on neix la poesia i és més que poesia. (1995b: 55)

Marçal ho fa en la novel·la La passió segons Renée Vivien:

A través de Renée em sembla haver arribat a entendre què vol dir allò de barrejar indestriablement vida i literatura, viure la vida "literàriament", potser millor, "poèticament": cada gest, cada moment és una figura retòrica, i sistemàticament, l'humil, limitat, pobre, significant sap que no està a l'altura del Significat escàpol: la part que es tesa i es trenca en el seu esforç per representar el Tot; el tot que s'adona, tristament, que no és el fons sinó una ínfima part." (1994: 334)

La vida i l'obra de Tsvetàieva ofereixen un lligam indestriable, així ho afirmava Maria-Mercè Marçal el 1997 en el que va constituir el seu darrer assaig literari: "Bona part dels seus poemes poden ser entesos com les pàgines d'un peculiar dietari, d'un dietari commovedor i de qualitat extraordinària" (1998: 157). Semblantment, apunta el poeta Joseph Brodsky:

La poeta Tvetàieva era idèntica a la persona Tsvetàieva; entre la paraula i l'acció, entre art i vida no hi havia per a ella cap coma ni cap guió; Tsvetàieva va posar entre les dues un signe d'igualtat: “No vull servir de trampolí per a les idees d'altres, tampoc d'altaveu per a les passions d'altres. (Komarov 1997: 86)

Una particularitat de la poesia de Tsvetàieva i Marçal que al mateix temps atrau i repèl és la seva sinceritat immensa. Tots els sentiments de les poetes són aguts i extraordinaris. Una poesia que Marçal tenia entre les més estimades; una poeta que Marçal considera “excepcional” i “inimitable” (Marçal 2014: 142 i 143).

Visc -i no necessito ningú!

Quan entres -no dormo gens.

Per escalfar un sopar

a l'altre -cremaré la meva llar. (Tsvetàieva 1994a: 562)

He estimat un arcàngel a ple vol,

seda de bosc als cabells $i$ a les ales.

He trencat als seus ulls com la mar a les cales

d'un país on les bruixes ja no duen més dol. (Marçal 2017: 198)

Tsvetàieva "viu amb el cor obert" (Kudrova 1991: 83); mentre Marçal escriu en el poema "Ruda": "I alçaré cor i vi perquè la vida guanyi: / el meu amor serà la ruda que t'estranyi“. (2017: 1985)

Tota la lírica de Tsvetàieva és molt tensa i plena d'energia, tant si parla del món com de les persones, i, sobretot, quan parla d'ella mateixa, el seu caràcter fort es reflecteix en les línies pesants dels seus versos:

No complia els manaments, no anava a la comunió. 
Sembla que fins que em cantin l'oració final, pecaré -com peco ara-com he pecat:

Amb tots els sentits donats pel Déu-

amb passió!

amb tots cinc. (1994a: 243)

No hi ha lloc per a la moderació: o sofriment extrem o un cant de joia. La nostra percepció de la seva poesia pot semblar una hipèrbole constant, però per a la poeta és la mida habitual de la seva existència. Ella mateixa afirma: "En res conec la mesura". La desmesura s'entén habitualment com una característica del caràcter rus, però Tsvetàieva força aquesta idea en posar-la en relació amb la de límit. Un element que en l'imaginari eslau és vist com a perill i, per tant, evitat (si ens fixem en contes populars i cançons de bressol sempre hi trobem una prevenció insistent per no traspassar els límits establerts). Aquest és exactament el concepte que trenca la poeta. Aquesta atracció per traspassar el límit sembla el seu desig constant i desplegat en qualsevol esdeveniment vital. "Diuen que l'alçada de les muntanyes es mesura per l'atracció vers un precipici“. (1994c: 26) Aquesta desmesura mai va facilitar l'existència de Marina Tsvetàieva.

D'altra banda, Marçal expressa els seus sentiments amb una gran tendresa:

Avui la primavera se m'ha fet tota meva

com una criatura: dóna més que no rep.

Ha pres a mà les regnes del meu cor, i l'estrep,

i desnua amb pols ferm la tristor que s'agleva. (2017: 152)

o d'una manera més brusca: "La nit em clava / el seu ullal / i el coll em sagna“. (2017: 79)

El naixement de l'Heura, la filla de Marçal, la tardor de 1980, es converteix en el triomf d'una maternitat assumida en solitari. Som en l'època que una societat encara estigmatitza la dona per les relacions sexuals fora del matrimoni canònic. Durant aquesta època la poeta catalana escriu intensament i la força de la seva passió amorosa s'abriva des d'un posicionament netament femení. Poeta vital, Marçal converteix l'espera i l'infantament en una autèntica festa del cos. És debades que busquem en la tradició literària occidental un cas similar d'una poeta que posi nom a la multitud de sentiments durant la gestació de l'infant. Marçal dedica al voltant de 25 poemes a la gestació; al llarg del novenari, mes a mes, amb imatges en què el desig de la filla se sumen a la tendresa i a la sensualitat més extrema:

\footnotetext{
Heura que m'envaeixes el ventre i la follia!

Freu entre el cel i l'aigua, ennuvolat de foc.

T'estimo: sóc la pluja que amara l'enderroc

D'on, tenaç, s'obre un fruit amb colors d'alegria.

Heura que véns de mar. Freu amb l'ona a ple brull.

L'estrall tot just et frega la pell: la vida es bada.

Per tu, jo seré el sol i la lluna granada

I una casa sense urc amb celler, pou i trull. (2017: 199)
} 
Són poemes d'una sensibilitat exquisida. Un cop nascuda la filla, l'alegria i el triomf s'imposen. S'inicia també la recerca d'una relació mare - filla que es vol lliure dels rols habitualment imposats, també el repte, la llibertat, la por, els dubtes:

Heura,

victòria marçal,

germana

estrangera, de cop feta present:

Com desxifrar el teu llenguatge bàrbar

i violent que força els meus confins

fins a la sang, un repte que no em deixa

ni les cames tan sols per a fugir!

[...]

I malgrat tot $\mathrm{t}^{\prime}$ anomeno victòria,

heura marçal, germana, l'estrangera. (2017: 284)

L'obra de la poeta russa reflecteix els seus sentiments; coneixem versos dedicats a persones diverses; tot un llibre, La història de Sónietxka, escrit arran de la mort de l'actriu Sofia Gollidei el 1937 i que la transporta a l'any 1919 quan s'hi relacionava. I més, hi ha les cartes. S'hi mostra sempre extravertida, desbordant, hi flueix la seva imaginació, trasllada la conversa a un ésser imaginat i líric.

Els seus corresponsals (Pasternak i Rilke entre altres) se sentien implicats i incòmodes per aquest sentiment tant fort que sempre mostrava Marina Tsvetàieva. El crític literari Alexandr Bakhrakh, per exemple, va deixar d'escriure-la, espantat (Kudrova 1991: 63-64). Però, de fet, no entenien que aquest sentiment només existia en ella: “A la vida no m'agradaven les cites -xoquem amb els fronts. Dos murs impenetrables, incomprensibles" (Tsvetàieva 1995a: 226). Les cartes serveixen a Tsvetàieva per expressar-se amb més plenitud fins que descobreix, la dècada dels 1930, el gènere nou per a ella, la prosa lírica.

Es va mantenir fidel a aquesta visió de la passió fins al final de la seva vida: "Sempre vull dir, cridar: Déu meu! No vull res de vostè. Vostè pot sortir i tornar, sortir i no tornar mai -tant m'és, sóc forta, no necessito res més, només la meva ànima." (Tsvetàieva 1995a: 25)

En la poesia de Marina Tsvetàieva i Maria-Mercè Marçal es copsa una veu forta i segura, la veu d'una persona independent i convençuda de posseir el dret a la llibertat interior, a triar el seu camí.

No és gens estrany que aquesta actitud personal-poètica pugui sobtar i portar a la solitud, tan sovint esmentada per les dues poetes:

m'és indiferent on sentir-me sola (Tsvetàieva 1994b: 315);

Com un peix sense bicicleta / cerco el meu cor entre les ones. / Alço la copa on mor la lluna / en vi molt dolç. / M'he emborratxat de solitud. (Marçal 2017: 85);

Les hores dansen / sobre la meva pell / i ve la solitud / de peus menuts, / sense sabates... (Marçal 2017: 91) o

Sola, ben sola, em diu aquest mirall. (Marçal 2017: 109). 
Molts dels poemes tardans de Tsvetàieva són difícils d'entendre. La seva dificultat no és un acte conscient de la poeta, és un fenomen que demostra la complexitat de les idees descobertes per l'art modern i l'ús innovador del llenguatge poètic (Kudrova 1991: 126). Ella mateixa entenia que no podia arribar a tothom, però no sabia condescendir. No obstant existien persones a qui considerava amb una força similar a la seva, com V. Maiakovski, B. Pasternak, A. Akhmàtova i R. M. Rilke.

El 1989 Maria-Mercè Marçal publica Llengua abolida, que recull tota la seva obra poètica escrita fins al moment. Autora d'un públic fidel i nombrós des de l'inici, comença a ser una escriptora reconeguda i una figura controvertida, incòmoda, perquè la seva vida es mou en una heterodòxia radical i assumida literàriament $\mathrm{amb}$ total coherència.

\section{LA POETA I LA POESIA}

Tot poeta, al llarg de la seva vida i especialment en els seus anys de maduresa, està preocupat per la importància que la seva obra té en la societat, pels lectors que s'ha guanyat i, en general, pel sentit de la creació poètica. Per això aquest motiu no és casual en els versos d'ambdues poetes.

"Només soc una petxina en la qual l'oceà encara no ha parat de ressonar" (1994a: 285) -d'aquesta manera Tsvetàieva entén l'objectiu del poeta: sentir i expressar la realitat, l'existència, els impulsos profunds de la vida i bastir-los amb les paraules. Tot existeix en aquest món, tot està diluït i només un artista pot extreure-ho, entendre-ho i anomenar-ho en la seva obra:

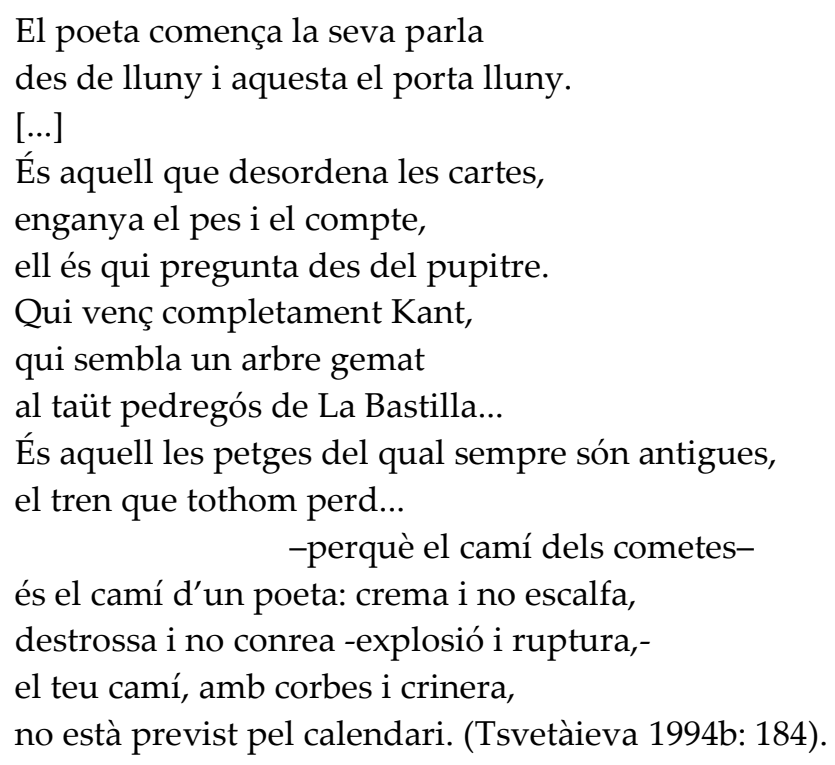

Cal destacar una certa proximitat del seu punt de vista al d'un altre poeta rus: Borís Pasternak. "Escric per arribar a l'essència, per revelar-la" -són les paraules de Marina Tsvetàieva (1995b: 377); “En tot voldria arribar a l'essència” -és el títol d'un poema de Pasternak. 
Són curiosament contraposades les comparacions que utilitza Marina Tsvetàieva per crear la imatge del poeta; d'una banda hi ha el rossinyol i les flors que creixen lliurement, i, de l'altra, una flama de la foguera, on ell es crema i reneix com l'au Fènix i la sang de les pròpies venes:

He obert les venes: imparable

s'escola la vida sense esment.

Poseu-hi a sota els plats i els bols!

Qualsevol plat serà massa pla,

i el bol-massa petit.

Sobreïx del cantó- fins

a la terra negra per alimentar el jonc.

Sense retorn, imparable,

s'escola el vers. (1994b: 315)

Però totes les imatges tenen un tret comú: reflecteixen la manera de ser de la mateixa Tsvetàieva, la intensitat dels sentiments. El seu rossinyol no canta, sinó que "esquinça les cordes vocals fins que no n'hi queda cap de sencera" (1994a: 449) de tant d'esforç fet.

Tsvetàieva compara freqüentment el poeta amb un cavall. No evoca el "pegasus" mític sinó que el poeta és el corser, independent, orgullós, resistent: "El meu cavall prefereix una carrera de bogeria!" (1994a: 181)

Tot i que per un poeta no hi ha la vida sense escriptura, habitualment no existeixen les condicions favorables, com va afirmar Tsvetàieva en l'assaig Natàlia Gontxarova: "qualsevol procés de creació [...] assumeix una superació i colpeja (amolla) de la vida encara que aquesta sigui feliç". (Kudrova 1991: 211)

Marçal acudeix a la poesia per entendre's i explicar-se a ella mateixa:

A les paraules demano camins

que ens assenderin les noves petjades.

Uns altres llavis que deixin carmí

en els vidres extrems de vells miratges.

Noves mans, llengua nova, nous sentits.

Uns nous camins excavats sang a sang. (2017: 356)

L'escriptura és una forma d'exploració interna que sorgeix de forma espontània en ella, com una activitat vertebradora del seu ser:

Durant molts anys he escrit només, o fonamentalment, poesia, i la poesia ha estat el meu esquelet intern, la meva manera de dir-me a mi mateixa, d'ordenar provisionalment amb la paraula el caos que l'imprevist desencadena... (Marçal 2004: 21)

Marçal explora i aprofundeix aquesta actitud sense treva. També vetlla per fer de l'escriptura un procés constructiu, positiu, davant de la vida, però en mirar i analitzar el seu voltant, ha de convenir que les formes i funcions assignades a la dona, li són francament adverses. Primer més intuïtivament després de forma 
més reflexiva, la poeta reafirma aquesta voluntat de construir una identitat femenina en què les dones s'hi puguin veure representades, emmirallades:

\author{
El fum dibuixarà \\ l'inici de la història \\ com una heura de joia \\ entorn del nostre cos \\ i plourà i farà sol \\ i dansarem a l'aire \\ de les noves cançons \\ que la terra rebrà. \\ Vindicarem la nit \\ i la paraula DONA. \\ Llavors creixerà l'arbre \\ de l'alliberament. (Marçal 2017: 142)
}

Malgrat que Marina Tsvetàieva, amb un comentari molt subtil, suggereix que les obres literàries són passatgeres, com a qualsevol poeta es preocupa pel llegat poètic que pugui deixar: "Hi ha un amor secret / Enmig d'un foc i un text! / El manuscrit desitja un foc... " (1994b: 97), per ella el destí dels seus versos és evident, és per això que ella mateixa s'anomena l'au Fènix:

Soc l'au Fènix, només canto en una flama!

Doneu suport a l'alçada de la meva vida!

La foguera s'alça i em cremo a terra,

Il-luminant-vos la foscor de la nit. (1994a: 425)

Uns termes que han estat apuntats en el títol d'un dels llibres més sobresortints de la poeta russa: La vida de Tsvetàieva. L'au Fènix immortal (Saakyants 2002).

Al seu torn, en l'últim text assagístic que va escriure Marçal, insisteix en aquest aspecte:

Què vol dir aquest desig de "fins i tot després de morir seguir escrivint"? Al meu entendre, no és només allò del "dur desig de durar" que deia Paul Éluard... no només el desig que les pròpies paraules restin i perdurin. Sinó el fet que siguin llegides com a noves en nous contextos i així prenguin nous significats, siguin nou aliment, nova sang per a un públic lector. (Marçal 1999: 9)

I sempre com a revolta, com reflecteix aquest poema, on descriu seguint la imatge bíblica de la lluita entre David i Goliat, la seva poètica: la paraula, un còdol:

Enmig de murs d'escòria, de ferralla, una paraula, minúscula potser, i tota rovellada pel rellent de tantes nits mal closes.

Una paraula, polida com un còdol

per les riades, colgada per l'oblit 
sota un bosc de paraules que l'estrafan, que usurpen

el seu espai desert, el seu nom insabut. (2017: 399)

L'actitud d'un gran poeta consisteix en representar -intuïtivament o amb plena consciència- la pròpia època i presentar alguna cosa per a la qual no ha arribat encara el temps. Aquest fou l'objectiu de Marçal que li permet ocupar un lloc important en la literatura catalana i europea, i explica l'interès persistent a la seva obra a través d'estudis, traduccions, poetes de generacions posteriors que la llegeixen i hi dialoguen o posant-hi veu i música als seus versos.

Si ens referim a Tsvetàieva, al costat de Maiakovski, Pasternak i Mandelshtam, la poeta crea una nova llengua poètica adequada per a la percepció de la gent del segle XX. Curiosament $-\mathrm{o}$ potser pel seu caràcter independent- Tsvetàieva no pertanyia a cap escola o grup poètic. Però sembla que les tendències futuristes de Maiakovski li semblaven molt adequades per a l'època. Un aspecte, l'avantguarda, que acosta novament les dues poetes.

Marçal no treballa des de la negació del món heretat, sinó des de la seva subversió, des del capgirament d'aquelles imatges poètiques, vells conceptes fixats, per a construir-hi un univers inèdit que representi la identitat femenina en positiu. En els primers reculls -Cau de llunes i Bruixa de dol-el to és molt més reivindicatiu, en consonància amb la lluita política i feminista d'aquells anys; però, al mateix temps, és d'aquesta anàlisi a fons de la representació dels papers atorgats a la dona que Marçal pot iniciar la seva obra assumint i subvertint alhora les imatges-concepte a què ha estat reduïda la dona: "Passivitat, Lluna, Naturalesa, Nit, Mare, Sentiment, Sensible, Pathos, Matèria, Receptacle".

Al lector, el món poètic de Marçal li pot semblar molt conegut, normal i, fins $\mathrm{i}$ tot, primari per les seves imatges, però d'una riquesa d'excepció capaç de donar significat a molts sentiments, emocions i conceptes:

\footnotetext{
Pujaré la tristesa dalt les golfes

amb la nina sense ulls i el paraigua trencat,

el cartipàs vençut, la tarlatana vella.

I baixaré les graus amb vestit d'alegria

que hauran teixit aranyes sense seny (2017: 94)
}

Marçal treballa amb els elements primigenis, bàsics i, per tant, centrals en l'imaginari col-lectiu: la lluna, imatge dominant en els tres primers reculls, el mar i la sal, acròstic del seu nom, el foc; elements que tracen un periple espacial fins a portar-la a la terra, a una nova terra que ja res té a veure en el receptacle fecund que durant segles l'ha devastada:

Iniciem la Història. Acabem

amb el segrest de l'aigua i amb l'imperi

del foc i el ferro. Inundem-nos amb fulles

de la tendresa! (2017: 229) 
Un altre tema a desenvolupar -i que ara sols en fem una breu referència- és el dels recursos de la llengua que han de permetre al poeta fer escoltar la seva veu.

En el cas de Marçal, és evident la introducció de mots i expressions de l'Urgell, la terra nadiua en relació amb la poesia culta (vid. Julià 2001: 6-23) o l'article d'Antoni Pladevall on diu:

«la seva poesia -la seva escriptura en general- és molt sonora i rítmica, molt rica i dúctil, [...] hi pesen, en grau divers, les empremtes de dues realitats lingüístico-literàries fonamentals que, ben combinades, procuren la bellesa, la precisió i l'exigència formal de tota la seva escriptura: 1) La llengua viva del seu Ivars d'Urgell natal. [...] 2) La llengua literària». (Pladevall 2010: 21)

El caràcter fort i apassionat de Tsvetàieva es reflecteix p. ex. en els seus versos amb les línies curtes i pesants. La poeta utilitza amb molta eficàcia tots els recursos verbals i gràfics possibles (vid. Révzina 2009). En aquest sentit, els guions esdevenen un "marca" que caracteritza el trencament dels versos. Un aspecte que fins i tot Marçal utilitza en la seva prosa i en alguns versos últims.

\section{LA POETA I L'AMOR}

Tant Marina com Maria-Mercè eren dones d'una indubtable atracció física. I, a més, apassionades, aventureres en els camins de l'amor, possessives i exclusivistes fins a la desmesura. Més que dirigir les seves vides sentimentals, es deixen dur pels impulsos, per l'atzar, per aquelles altres zones humanes que no es deixen explorar als ulls de la raó: "d'aquesta manera s'enamoren de l'amor, cauen al precipici" (Tsvetàieva 1994b: 194).

En les obres de totes dues hi és central la passió amorosa i el desig, la passió encesa i la decepció malastruga, l'amor i desamor, l'amor i l'absència de l'altre/a veïnegen. En parlar de la passió amorosa de Marina Tsvetàieva, Marçal diu: “No és estrany que per a Marina la paraula amor sigui ben aviat i durant tota la vida sinònima d'absència i, encara més, de trencament." (Marçal 1998: 161).

D'altra banda, la mateixa Marçal va viure "a mercè de l'amor" de Mai durant anys, i això que la relació havia estat molt breu. No se' $n$ sabia desprendre, com mostra els nombrosos poemes que dedica, també ella, al trencament:

\footnotetext{
Et maleeixo, Mai, perquè has vençut.

Perquè has sabut que sols triomfaries

llegant-me la teva ombra, en un record

que té la forma d'un estoig sagnant.

Perquè fugires deixant-me a les mans

la teva absència i una derrota.

I és per això també que et beneeixo. (2017: 337)
}

Ramon Llull va dir "si no ens entenem pel llenguatge, entenguem-nos per amor." Aquestes paraules tant habitualment utilitzades per explicar les relacions 
amoroses són contradites per l'experiència de Marina Tsvetàieva, per a ella l'amor se situa més enllà de les persones, se centra i s'expressa en el llenguatge mateix. Molt aviat va sentir en si mateixa una cremor secreta, un motor amagat de la vida i el va anomenar "l'amor".

Quan tenia sis anys a través d'una actuació nadalenca va conèixer una història tràgica $\mathrm{d}$ 'amor entre Tatiana i Oneguin, els protagonistes de la novel-la en vers Ievgueni Oneguin d'A. Puixkin. La nena s'obsessiona pels personatges i s'enamora de Tatiana. Més tard ho reflectirà en l'assaig El meu Puixkin i escriurà: "Puixkin em va contagiar l'amor. Amb la paraula- amor." (Tsvetàieva 1994e: 68). La seva actitud a l'amor és bent clara $i$, en aquest sentit, els dos versos darrers són ben il-lustratius: “O amor, que salva el món! / Només en ell trobem salvació i protecció". (Tsvetàieva 1994a: 18)

Tsvetàieva va viure períodes feliços d'amor. Amb Serguei Efrón, el seu marit, amb Sofia Parnok, poeta reconeguda, o amb Constantin Rodzevitx, un jove intèrpret i pintor rus que va conèixer a l'estranger. Dedica a cadascú part de la seva obra: molts versos a Efrón, el cicle Amiga a Parnok, Poema de la fi a Rodzevitx. La seva passió era viscuda a través de la paraula.

Però també va entendre -sols amb sis anys- que la seva passió seria impossible. Des d'aquell moment no es va permetre ser feliç, es va condemnar al desamor. Això es destaca perfectament en la seva correspondència amorosa molt extensa.

El 1982 Maria-Mercè Marçal publica a València les quinze sextines de Terra de mai. Són el primer referent desbridat de l'amor "conjugat en femení" de la literatura catalana. Es tracta d'un breu i dens poemari sorgit de la relació amb Mai, un nom que conté en ell mateix la passió i la seva impossibilitat: Mai. S'inicia des del punt àlgid de l'amor, de la trobada amorosa els poemes passen, paulatinament, a ser mirall de l'absència de qui l'abandona; $i$, doncs, frustració $i$ anhel de l'altra, i exigència i súplica del seu retorn. Després tindrà diverses relacions amoroses que han deixat una petja important en la seva obra, però és amb Fina Birulés, a qui coneix el 1984, amb qui mantindrà la relació més important. És una relació fecunda també pel que fa a la reflexió literària.

Cal destacar que l'amor il-limitat és un concepte comú en l'obra de les dues poetes. M. Tsvetàieva afirma: "estima sense límits i fins el fi!" (1994a: 59), "no he après a estimar a la meitat" (1994a: 231), "sense paraules amar..." (1994b: 131). L'actitud de la poeta catalana ha estat repetidament analitzada i posada en relleu. La passió la vol viure sense límits. El cos de l'altra esdevé un territori a explorar (Riba 2015: 115-125).

\section{MARINA TSVETÀIEVA I MARIA-MERCÈ MARÇAL: POSSIBILITAT D'UN DIÀLEG}

Introduir aquí una noció del diàleg no seria cap disbarat. Marina Tsvetàieva i Maria-Mercè Marçal són participants del procés literari, que inicia un diàleg sobre el "camp" del text malgrat que els "intermediaris" del diàleg pertanyen a 
les literatures nacionals diferents. Aquest diàleg és un fenomen científic que s'utilitza com una tècnica en els estudis de literatura comparada, habitualment és un diàleg imaginari (vid. Làskina 2018).

En el cas estudiat també és suposat, perquè ha sorgit independentment dels contactes de participants (Maria-Mercè Marçal va néixer onze anys després de la mort de Marina Tsvetàieva; tampoc va poder conèixer tota l'obra de la poeta russa).

El concepte d'un text entès com acumulador de pràctica cultural, com una experiència (vid. Gaspàrov 1996) és coherent als textos de Maria-Mercè Marçal i de Marina Tsvetàieva. Els seus versos s'entrellacen en un diàleg poètic constant que ens revela l'experiència acumulada d'una dona i poeta molt semblant, l'experiència que reflecteix uns aspectes comunicatius, espirituals, i creatius de la seva activitat poètica.

Com que "un text només viu en contacte amb un altre text (context); només al punt d'aquest contacte dels textos es fa un flaix de llum, il·luminant-se d'anada i tornada, introduint aquest text al diàleg“ (Bakhtin 1979: 384), els textos de Marina Tsvetàieva i Maria-Mercè Marçal, formant el diàleg poètic, il·luminen uns nous camins pels lectors i investigadors.

En aquest apartat darrer ens hem permès de reunir uns pocs exemples entre molts descoberts a l'hora de preparar aquest estudi comparatiu que formen part del diàleg poètic.

Així, el nom; la forma d'autopresentació poètica:

Un fet de pedra, l'altre de fang,-

però jo sóc de plata, i brillo!

El meu destí és traïció, el meu nom -Marina,

jo sóc escuma efímera de la mar. (Tsvetàieva 1994a: 534)

Mercè de sal a mercè del desig,

per l'esglai sense platges del teu nom,

duc el meu cor pres en xarxa de plata,

com un gran peix, nàufrag de la tempesta.

¿Trobarà mar, pels camins del teu cos,

o morirà dins el meu cos voraç? (Marçal 2017: 254)

$\mathrm{o}$

Emmarco amb quatre fustes

un pany de cel i el penjo a la paret.

Jo tinc un nom

i amb guix l'escric a sota. (Marçal 2017: 75)

La noció de la poesia com la sang, un nou aliment per alimentar els lectors:

He obert les venes: [...]

Sense retorn, imparable,

s'escola el vers. (Tsvetàieva 1994b: 315)

Un polsim de sang 
-com sal engrunada

damunt la ferida-

damunt d'aquest àpat. (Marçal 2017: 328)

Les imatges femenines en les dues poetes mostren una sensibilitat exquisida i triomf del cos femení:

\author{
Els meus pits són dos ocells engabiats \\ quan els teus dits els cerquen \\ per entre les fulles i les flors del vestit. \\ Però quan fulles i flors cauen a terra \\ que el desig porta dalla!- \\ són dos peixos que et fugen de les mans \\ en les crestes nevades de la mar. (Marçal 2017: 97) \\ El pit femení! És un sospir aturat de l'ànima. \\ I l'essència femenina és una ona sempre presa \\ per sorpresa. I sempre et pren per sorpresa. (Tsvetàieva 1994b: 69)
}

Aquesta sensibilitat troba un èmfasi complet en la puntuació dels versos i les rimes, els cal-ligrames de Marçal o una determinada ús ortogràfic en Marina Tsvetàieva:

Un signe d'amor i bogeria

És el signe d'exclamació! (Tsvetàieva 1994a: 197)

$X Y X Y X Y X Y$

$X Y X Y X Y X X$

$X Y X Y X Y X Y$

$X Y X Y X Y X X$

Continueu la sèrie encetada.

És l'esquelet: poseu-hi l'arracada. (Marçal 2017: 507)

Les dues poetes treballen amb la paraula, perquè tant Tsvetàieva com Marçal comparteixen la idea del poeta visionari que es deu a la seva obra, i les dues poetes ho fan a través de la vida, del desig i la passió amorosa en primer terme, però també des de la necessitat de viure amb excés.

Sembla que en relació a les obres literàries, especialment poètiques, de Tsvetàieva i Marçal es pot emprar el concepte de convergència (conformitat) tipològica (o comunitat tipològica, en la terminologia de N. Konrad (vid. Konrad 1973)), que s'utilitza per denotar fenòmens similars en diferents literatures que són el resultat de diferents etapes del desenvolupament sociohistòric i cultural dels pobles o -més aviat, en el cas estudiat- de lleis universals de consciència humana.

En aquest sentit, les obres de ambdues tracen un diàleg constant sobre el "camp" dels textos pertanyents a diferents literatures nacionals, però units per les nocions bàsiques i comunes a una dona que se submergeix en la poesia. 
Per molt que sigui una tècnica en els estudis de literatura comparada, aquest diàleg també pot resultar important per la visió holística de la poesia: "la fórmula de traçar rutes imaginàries ajuda a explorar i a fer aproximaciones abstractes" (Contijoch, 2006: 25-26). El diàleg entre Tsvetàieva i Marçal, complex pels seus contingut i forma, és un fenomen estètic, un fenomen cultural comú únic.

\section{BIBLIOGRAFIA}

BAKHTIN, M.M. (1979), Estetika slovesnogo tvorchestva [Estètica de la creació verbal], Moscou, Iskusstvo.

CONTIJOCH, J. (2006), “La claror (La paraula en Maria-Mercè Marçal)”, Rels, revista d'idees i cultura, 8, 25-27.

DIMA, A. (1969), Principii de literatură comparată, Bucarest, Ed. pentru Liter.

DURIŠIN, D. (1974), Sources and systematics of comparative literature, Bratislava, Univerzita Komenskeho.

GASPÀROV, B.M. (1996), Yazyk, pamyat', obraz. Lingvistika yazykovogo sushchestvovaniya [Llenguatge, memòria, imatge. Lingüística de l'existència del llenguatge], Moscou, Novoe literaturnoe obozrenie.

Julià, L. (Ed.) (1998), Àlbum Marçal Maria-Mercè, Barcelona, Centre Català del PEN Club, Proa.

Julià, L. (2001), "Introducció", a Marçal Maria-Mercè. Contraban de llum. Antologia poètica, Barcelona, Proa, 5-53.

Julià, L. (2010), “De Brossa als trobadors i a Ausiàs March. Maria-Mercè Marçal, el diàleg amb la pròpia tradició", a II Jornades Marçalianes. Col.lecció Quaderns, 2, Fundació Maria-Mercè Marçal, 37-54.

Julià, L. (2017), Maria-Mercè Marçal. Una vida, Barcelona, Galàxia-Gutenberg.

KARLINSKY, S. (1986), (trad. de Segovia Fr.), Marina Tsvietáieva, Madrid, Ed. Grijalbo.

Komarov, G.F. (Ed.) (1997), Brodskiy o Tsvetaevoy: interv'yu, esse [Brodsky sobre Tsvetàieva: entrevistes, assaigs], Moscou, Nezavisimaya gazeta.

KONRAD, N.I. (1973), Ocherki yaponskoy literatury. Stat'i $i$ issledovaniya [Esbossos de la literatura japonesa. Articles i estudis], Moscou, Khudozhestvennaya literatura.

Kudrova, I.V. (1991), Versty, dali... Marina Tsvetaeva: 1922-1939 [Kilòmetres, distàncies... Marina Tsvetàieva: 1922-1939], Moscou, Sov. Rossiya.

LASKINA, N.O. (2018), "Marina Tsvetaeva i Anna de Noay: vozmozhnost' dialoga" [Marina Tsvetàieva i Anna de Noay: la possibilitat de diàleg], Kritika i semiotika, 1, 139-151.

MARÇAL, M.-M. (1994), La passió segons Renée Vivien, Barcelona, Proa.

MARÇAL, M.-M. (1998), “Com en la nit, les flames. Anna Akhmàtova - Marina Tsvetàieva", a Cartografies del desig, Barcelona, Proa (Col-lecció Ossa Menor), 157192.

MARÇAL, M.-M. (1999), “Pròleg”, a (Julià L. ed.), Memòria de l'aigua. Onze escriptores i el seu món, Barcelona, Ed. Proa (Col-lecció La mirada Literària, 37), 9-12.

MARÇAL, M.-M. (2004), Sota el signe del drac. Proses 1985-1997, a cura de Ibarz M., Barcelona, Proa.

MARÇAL, M.-M. (2014), El senyal de la pèrdua. Escrits inèdits dels últims anys, Barcelona, Ed. Empúries, Col-lecció Narrativa. 
MARÇAL, M.-M. (2017), Llengua abolida. Poesia completa 1973-1988, Barcelona, Ed. 62, Col·lecció La Butxaca.

PladeVAll, A. (2010), “L'emprenta dels clàssics grecollatins en la poesia de Maria-Mercè Marçal", a II Jornades Marçalianes. Col.lecció Quaderns, 2, Fundació Maria-Mercè Marçal, 21-35.

RÉvZINA, O.G. (2009), Bezmernaya Tsvetaeva: opyt sistemnogo opisaniya poeticheskogo idiolekta [Tsvetàieva infinita: l'experiència d'una descripció sistèmica d'un idiolecte poètic], Moscou, Dom-muzey Mariny Tsvetaevoy.

RIBA, C. (2012), L'obra poètica de Maria-Mercè Marçal: una aproximació des dels estudis de gènere i la literatura comparada [tesi doctoral], Vic, Universitat de Vic.

SAAKYANTS, A. (2002), Zhizn' Tsvetaevoy. Bessmertnaya ptitsa-feniks [Vida de Tsvetàieva. L'immortal au Fènix], Moscou, Tsentrpoligraf.

SISTAC, D. (2001), Líriques del silenci. La cançò de dona a Safo, Renée Vivien i Maria Mercè Marçal, Lleida, Pagès editors.

SKRIPOVA, O.A. (2005), “«Poetika predel'nosti» v «Poeme kontsa» Mariny Tsvetaevoy" [Poètica de les limitacions al Poema de la Fi de Marina Tsvetàieva], Filologicheskiy klass, 14, 82-87.

STAROVOITOVA, O. (2000), “La muerte del poeta y su reflexión en las obras literarias: Mandelshtam, Shalámov, Herling-Grudzinsky", Anuari de Filologia. Filologia romànica, XXII, G, 10, 87-97.

TSVETÀIEVA, M. (1994a), Sobranie sochineniy $v 7 t$. T. 1. Stikhotvoreniya [Obres recollides en 7 volums. Vol. 1. Poemes], Moscou, Ellis Lak.

TsvetÀIEVA, M. (1994b), Sobranie sochineniy v 7 t. T. 2. Stikhotvoreniya. Perevody [Obres recollides en 7 volums. Vol. 2. Poemes. Traduccions], Moscou, Ellis Lak.

Tsvetàieva, M. (1994c), Sobranie sochineniy v 7 t. T. 3. Poemy. Dramaticheskie proizvedeniya [Obres recollides en 7 volums. Vol. 3. Poemes. Obres dramàtiques], Moscou, Ellis Lak.

TSVETÀIEVA, M. (1994d), Sobranie sochineniy v 7 t. T. 4. Vospominaniya o sovremennikakh. Dnevnikovaya proza [Obres recollides en 7 volums. Vol. 4. Memòries sobre contemporanis. Diari en prosa], Moscou, Ellis Lak.

TsvetàIeva, M. (1994e), Sobranie sochineniy v 7 t. T. 5. Avtobiograficheskaya proza. Stat'i. Esse. Perevody [Obres recollides en 7 volums. Vol. 5. Prosa autobiogràfica. Articles. Assaigs. Traduccions], Moscou, Ellis Lak.

TsvetÀIEVA, M. (1995a), Sobranie sochineniy v 7 t. T. 6. Pis'ma [Obres recollides en 7 volums. Vol. 6. Cartes], Moscou, Ellis Lak.

TsvetàIeVA, M. (1995b), Sobranie sochineniy v 7 t. T. 7. Pis'ma [Obres recollides en 7 volums. Vol. 7. Cartes], Moscou, Ellis Lak.

Tsvetàieva, M. (2009²), (trad. de Zgustová, M. i Marçal, M.-M.), Poema de la fi. Edició bilingüe, Barcelona, Proa (1ª . edició, Eds. 62, 1992).

ZHIRMUNSKIY, V.M. (1978), Bayron i Pushkin [Byron i Puixkin], Leningrad, Nauka.

ZHIRMUNSKIY, V.M. (1960), "Problemy sravnitel'no-istoricheskogo izucheniya literatur" [Problemes d'estudi històric comparatiu de la literatura], Izvestiya AN SSSR. Otdelenie literatury i yazyka, XIX, 3, 177-186.

ZOLOT'KO, O.V. (2016), “"Stradaniya yunogo Vertera» Gete i «Son smeshnogo cheloveka» Dostoevskogo" ["Els sofriments del jove Werther" de Goethe i "El somni d'un home ridícul" de Dostoievski], Vestnik MGU Ser. 9, 1, 170-186. 